\title{
ABSENCE OF CLINICAL DISEASE IN SPITE OF A HIGH IN- CIDENCE OF CARRIERS OF GROUP A HEMOLYTIC STREPTOCOCCI OF A SINGLE TYPE; FAILURE OF TYROTHRICIN TO INFLUENCE THE CARRIER RATE
}

\author{
BY GEORGE HARTLEY, JR., JOHN F. ENDERS, J. HOWARD MUELLER, \\ AND EMANUEL B. SCHOENBACH \\ (From the Department of Bacteriology and Immunology, Harvard Medical School and \\ Harvard School of Public Health, Boston)
}

(Received for publication June 1, 1944)

Carriers of various pathogenic bacteria have long been recognized as a potential source of danger in causing outbreaks of disease. In spite of many attempts, as yet no entirely satisfactory means of eliminating pathogenic organisms from the upper respiratory tract has been found. Preliminary observations (1) suggested that tyrothricin (2) might be of value in treating convalescent scarlet fever patients carrying beta hemolytic streptococci. The number of individuals studied, however, was too small to provide conclusive evidence of the effectiveness of this antibiotic. Further studies were therefore undertaken in an institution ${ }^{1}$ where previous experience had shown that a high streptococcus carrier rate usually prevailed during the winter months and where frequent outbreaks of streptococcal pharyngitis had occurred.

As anticipated, the incidence of Group A streptococcus carriers in the institution proved to be high. In contrast to the experience of previous years, however, no disease attributable to these organisms was observed. The results of the daily topical application of tyrothricin and a discussion of the epidemiological findings are presented in this paper.

\section{MATERIAL AND METHODS}

The institution in which these studies were carried out was the Peabody Home for Crippled Children. In this home there were 76 children ( 40 boys and 36 girls), ranging from 2 to 16 years of age, who were suffering chiefly from chronic bone and joint diseases, such as tuberculosis and Legg-Perthe's disease. None of the children had any active pulmonary lesions during the course of this study.

1 We are indebted for this opportunity to the kind collaboration of Dr. G. N. Hoeffel, medical consultant to the Peabody Home.
Most of them had been at the home for several years, and some during 9 or 10 years, i.e., during almost their entire lives. No new children were admitted during the period of the study. About 60 per cent of the children were absolute bed-patients. These were segregated according to sex in 2 large wards. The beds were arranged side-byside, approximately 3 feet apart. The ambulatory children of both sexes attended school in the same class rooms and associated freely among the bed-patients of their sex. Also the nurses and attendants were in close and continuous contact with all the children. Therefore, ample opportunity existed for the spread of bacteria among the entire population of the home.

Throat swabs from each of the $\mathbf{7 6}$ children, taken once a week for 3 weeks, were cultured on peptone-blood agar plates containing no meat infusion broth (3) and examined for the presence of $\beta$-hemolytic streptococci. Following the third series of cultures, the noses and throats of all the boys were sprayed copiously twice daily with a suspension of tyrothricin prepared as follows: the appropriate volume of a known alcoholic solution of tyrothricin was added to the required amount of physiological saline containing $21 / 2$ per cent glycerine to give a final concentration of $0.34 \mathrm{mgm}$. per $\mathrm{ml}$. of the material. DeVilbiss atomizers were employed. After several weeks, the diluent was changed to 10 per cent dextrose in distilled water because the aqueousinsoluble suspension of tyrothricin is much finer in 10 per cent dextrose than it is in normal saline. The girls received no tyrothricin, thereby serving as controls. Approximately $5 \mathrm{ml}$. of the tyrothricin-suspension was sprayed into the nose and throat of each boy during each treatment. The children cooperated extremely well, except for 1 or 2 of the smaller ones, and quantities of the tyrothricin-suspension reached the rhinopharynx in each case which should have been adequate to cover the entire area. Weekly throat cultures were made during the course of the experiment with one exception. No toxic reactions whatever were noted during the course of the spraying or afterwards.

The in vitro bactericidal action of tyrothricin on 7 of the strains of $\beta$-hemolytic streptococci isolated from the children was determined. One ml. of graded amounts of tyrothricin, diluted in 10 per cent glucose in distilled water, was added to tubes containing $9 \mathrm{ml}$. of infusion 
broth. One tenth $\mathrm{ml}$. of an 18-hour infusion broth culture of the streptococcus was added to each of the tubes. The mixtures were incubated at $37^{\circ} \mathrm{C}$. for 24 hours when a portion of each was cultured on blood agar. After incubating at $37^{\circ} \mathrm{C}$. for 24 hours, the plates were examined for bacterial growth.

The $\beta$-hemolytic streptococci isolated from the throat cultures were grouped on 3 occasions before treatment with tyrothricin was initiated. Later, the organisms were grouped again and this time the bacteria belonging to Group A were typed. For both grouping and typing, the organisms were grown in $10 \mathrm{ml}$. infusion broth containing 1 per cent neopeptone, $1 / 4$ per cent table salt, and $1 / 2$ per cent disodium phosphate (3). The organisms were grouped by the formamide method (4) and were typed by the slide agglutination method. Before typing, the suspension of organisms was stabilized by adding one drop of Bacto-trypsin to the centrifuged culture of bacteria and allowing the mixture to stand overnight.

The pathological condition of the throat of each child was noted. Also, the number and severity of the upper respiratory infections and related diseases contracted during the course of the study were recorded.
RESULTS

The persistence of $\beta$-hemolytic streptococci in the throats of tyrothricin-treated and nontyrothricin-treated children

Figure 1 shows the percentage of throat cultures positive for $\beta$-hemolytic streptococci taken from a group of boys consisting on the average of 41 individuals and a group of girls comprised on the average of 36 individuals. In the majority of children, throat cultures were obtained each week during the period of study. In the case of certain individuals, the weekly culture was occasionally omitted. It is evident that spraying the noses and throats of the boys with tyrothricin did not reduce the $\beta$-hemolytic streptococcal carrier rate. The percentage of positive cultures among the boys was much higher than it was among the girls on each occasion save one, but the rise and decline of the incidence of positive

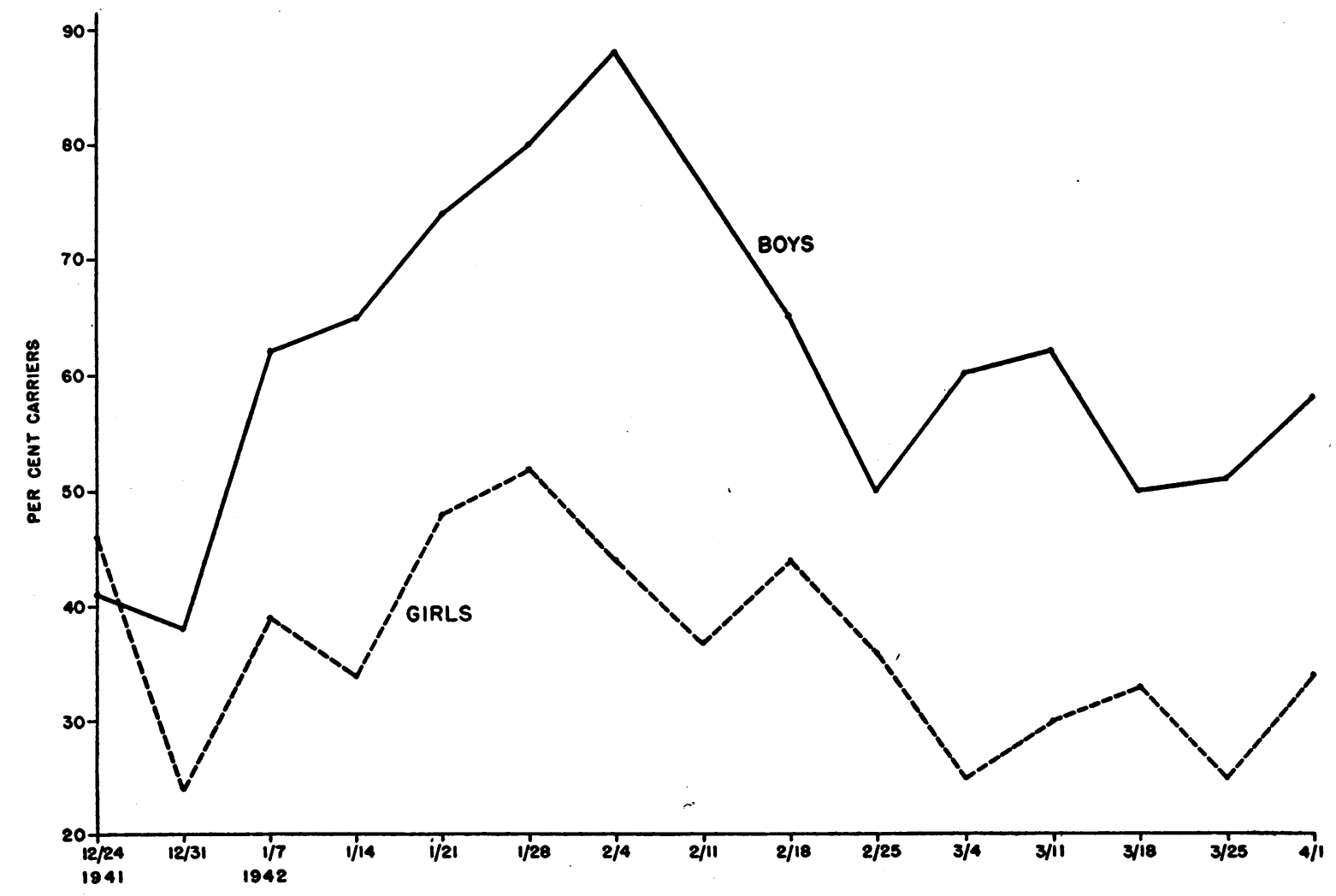

Fig. 1. Weekiy Incidence of Children Carrying $\beta$ Streptococci in the Throat, $1941-42$

No data derived from the cultures taken from the boys on 2/11/42 are recorded. The percentage of positive cultures was found to be so low at this time (about 30 per cent) that it was felt an error had been made in technic. 
TABLE I

The in vitro effect of tyrothricin upon 7 pharyngeal strains of $\beta$-hemolytic streptococci

\begin{tabular}{|c|c|c|c|c|c|c|c|}
\hline \multirow{2}{*}{ Amount of tyrothricin } & \multicolumn{7}{|c|}{ Strains of streptococci } \\
\hline & NA & DS & FG & WR & JC & EL & JH \\
\hline $\begin{array}{c}\text { Mg. } \\
169.0 \\
16.9 \\
1.69 \\
0.169 \\
0.0169 \\
\text { (Controls) } \\
0.0\end{array}$ & $\begin{array}{c}0^{*} \\
0 \\
0 \\
0 \\
0 \\
++++\end{array}$ & $\begin{array}{c}0 \\
0 \\
0 \\
0 \\
+++^{*} \\
++++\end{array}$ & $\begin{array}{c}0 \\
0 \\
0 \\
0 \\
+++++^{*} \\
+++\end{array}$ & $\begin{array}{c}0 \\
0 \\
0 \\
0 \\
+++t+t \\
++t+t\end{array}$ & $\begin{array}{c}0 \\
0 \\
0 \\
0 \\
0 \\
++++\end{array}$ & $\begin{array}{c}0 \\
0 \\
0 \\
0 \\
+++t+t \\
++t+\end{array}$ & $\begin{array}{c}0 \\
0 \\
0 \\
0 \\
0 \\
++++\end{array}$ \\
\hline
\end{tabular}

* Degree of growth on blood agar plates inoculated with organisms incubated for 24 hours in infusion broth to which graded amounts of tyrothricin had been added.

cultures in the two groups are closely parallel. It is noteworthy that a high incidence of positive cultures was obtained throughout the period of investigation from the entire population under observation.

\section{The "in vitro" action of tyrothricin on the strains of $\beta$-hemolytic streptococci obtained from the children at the institution}

When it became evident that the tyrothricin treatment was not causing any noticeable decrease in the incidence of the $\beta$-hemolytic streptococci in the throats of the children, the in vitro effect of the tyrothricin on the streptococci was determined. The results presented in Table $I$ indicate that all of the 7 strains of streptococci which were tested were susceptible to the in vitro action of tyrothricin since their growth was inhibited by 0.169 microgram or less of this substance per $10.1 \mathrm{ml}$. of culture.

\section{Grouping and typing of the $\beta$-hemolytic streptococci}

As previously stated, the $\beta$-hemolytic streptococci were grouped 3 times before and both grouped and typed once after the tyrothricin treatment was initiated. Table II shows that 28 of the 30 children who harbored Group A streptococci in their throats at the time the typing was done carried the same type, Type 11. The other 2 children carried Types 2 and 25, respectively.

The relationship between the persistence of the $\beta$-hemolytic streptococcic carrier state, the condition of the rhinopharynx, and the number and severity of upper respiratory infections of each individual
The fact that the percentage of positive carriers was considerably higher among the boys than it was among the girls suggested that among the former a greater incidence of abnormality of the throats might exist. Accordingly, a careful examination of the throats of all the individuals in the institution was made. Although the numbers are too small to permit the formulation of definite conclusions, a higher percentage of boys, namely 24 of the 40 as compared to 16 of the 36 girls, showed varying degrees of abnormal lymphoid tissue. The children with abnormal throat findings tended to be more consistent carriers than those whose throats appeared normal.

During the period of the study, 22 acute upper respiratory infections were observed. Sixteen cases developed among the boys of which 5 were moderately severe. Only 6 girls contracted infections; 2 were moderately severe and 4 were mild. In no instance were complications due to streptococci observed.

During the course of the study while the tyrothricin was being administered, a mild epidemic of whooping cough occurred in the home. Twelve of the girls and 6 of the boys developed the disease. There were no serious complications in any of these cases.

\section{DISCUSSION}

Although tyrothricin exerted a marked bactericidal action on the carrier strains of Group A hemolytic streptococci isolated from the children, the application twice daily of this antibiotic substance during 11 weeks failed to eliminate these organisms from the nasopharynx. It seems possible that the ineffectiveness of tyrothricin might 
be related to its insolubility in water and tissues. The persistence of the same pathogenic organisms in the upper respiratory tract suggests that they are not located merely on the surface of the mucous membranes but have penetrated into the deeper layers of the epithelium. In view of these findings, the previous encouraging results obtained in scarlet fever convalescents may well have been due to the spontaneous disappearance of the streptococci during the course of treatment but entirely independent of it.

TABLE II

The occurrence of $\beta$-hemolytic streptococci in the throats of children treated with tyrothricin and compared with an untreated group

\begin{tabular}{|c|c|c|c|c|c|c|}
\hline \multirow{2}{*}{ Patients } & \multicolumn{5}{|c|}{ Identification of $\beta$-hemolytic streptococcus } & \multirow{4}{*}{$\begin{array}{l}\text { Persistence } \\
\text { of strepto- } \\
\text { coccus* }\end{array}$} \\
\hline & & & & & Type & \\
\hline \multirow{2}{*}{ Boys } & & & & & Date & \\
\hline & $12 / 24$ & $12 / 31$ & $1 / 7$ & $3 / 11$ & $3 / 11$ & \\
\hline $\begin{array}{l}\text { L. B. } \\
\text { F. K. } \\
\text { H. C. } \\
\text { G. P. } \\
\text { R. T. } \\
\text { P. D. } \\
\text { A. A. } \\
\text { J. M. } \\
\text { P. F. } \\
\text { G. D. } \\
\text { R. L. } \\
\text { T. C. } \\
\text { M. C. } \\
\text { J. D. } \\
\text { D. D. } \\
\text { W. N. } \\
\text { G.St. A. } \\
\text { D. S. } \\
\text { N. A. } \\
\text { J. D. } \\
\text { L. A. } \\
\text { F. G. } \\
\text { H. C. } \\
\text { G. D. } \\
\text { C. L. } \\
\text { D. C. } \\
\text { J. H. } \\
\text { R. L. } \\
\text { N. DeB. } \\
\text { W. R. } \\
\text { E. L. } \\
\text { J. C. } \\
\text { F. I. } \\
\text { G. M. } \\
\text { T. M. } \\
\text { M. G. } \\
\text { R. D. } \\
\text { N. G. } \\
\text { R. B. } \\
\text { G. P. }\end{array}$ & Xy & $\begin{array}{l}\mathbf{A} \\
\mathbf{A} \\
\mathbf{C} \\
\mathbf{A} \\
\mathbf{A} \\
\\
\mathbf{A}\end{array}$ & $\begin{array}{l}\text { A } \\
\mathbf{C} \\
\mathbf{A} \\
\\
\mathbf{A} \\
\mathbf{A} \\
\mathbf{A} \\
\\
\mathbf{C} \\
\mathbf{A} \\
\mathbf{A} \\
\mathbf{A} \\
\mathbf{A} \\
\mathbf{A} \\
\mathbf{A}\end{array}$ & $\begin{array}{l}\mathbf{A} \\
\mathbf{A} \\
\mathbf{C} \\
\mathbf{A} \\
\mathbf{A} \\
\mathbf{A} \\
\mathbf{A} \\
\mathbf{A} \\
\mathbf{C} \\
\mathbf{A} \\
\mathbf{A} \\
\mathbf{A} \\
\mathbf{A} \\
\mathbf{C} \\
\mathbf{A} \\
\mathbf{A} \\
\mathbf{C} \\
\mathbf{A} \\
\mathbf{C} \\
\mathbf{A} \\
\mathbf{A} \\
\mathbf{A} \\
\mathbf{A} \\
\mathbf{A}\end{array}$ & $\begin{array}{l}11 \\
11 \\
11 \\
11 \\
11 \\
11 \\
11 \\
11 \\
11 \\
11 \\
11 \\
11 \\
11 \\
11 \\
\\
11 \\
11 \\
11 \\
11 \\
11\end{array}$ & $\begin{array}{r}\text { O } \\
\text { O } \\
\text { I } \\
\text { II } \\
\text { I } \\
\text { I } \\
\text { I } \\
\text { III } \\
\text { II } \\
\text { IV } \\
\text { II } \\
\text { II } \\
\text { II } \\
\text { I } \\
\text { II } \\
\text { III } \\
\text { III } \\
\text { IV } \\
\text { IV } \\
\text { II } \\
\text { III } \\
\text { IV } \\
\text { IV } \\
\text { III } \\
\text { IV } \\
\text { IV } \\
\text { IV } \\
\text { III } \\
\text { II } \\
\text { III } \\
\text { IV } \\
\text { IV } \\
\text { II } \\
\text { II } \\
\text { I } \\
\text { II } \\
\text { I } \\
\text { I } \\
\text { II } \\
\text { II }\end{array}$ \\
\hline
\end{tabular}

$* 0=$ No positive throat culture obtained at any time; I to IV = positive cultures obtained from 1 to 100 per cent of the time.
TABLE II-Continued

\begin{tabular}{|c|c|c|c|c|c|c|}
\hline \multirow{4}{*}{$\begin{array}{l}\text { Patients } \\
\text { Girls } \\
\end{array}$} & \multicolumn{5}{|c|}{ Identification of $\beta$-hemolytic streptococcus } & \multirow{4}{*}{$\begin{array}{l}\text { Persistence } \\
\text { of strepto- } \\
\text { coccus* }\end{array}$} \\
\hline & \multirow{2}{*}{\multicolumn{4}{|c|}{$\frac{\text { Group }}{\text { Date }}$}} & \multirow{3}{*}{$\begin{array}{c}\text { Type } \\
\text { Date } \\
3 / 11\end{array}$} & \\
\hline & & & & & & \\
\hline & $12 / 24$ & $12 / 31$ & $1 / 7$ & $3 / 11$ & & \\
\hline $\begin{array}{l}\text { M. L. } \\
\text { M. L. } \\
\text { B. R. } \\
\text { P. R. } \\
\text { A. M. } \\
\text { D. W. } \\
\text { L. P. } \\
\text { J. B. } \\
\text { J. L. } \\
\text { M. L. } \\
\text { P. B. } \\
\text { A. L. } \\
\text { B. S. } \\
\text { F. D. } \\
\text { S. B. } \\
\text { C. T. } \\
\text { E. E. } \\
\text { N. J. } \\
\text { J. W. } \\
\text { H. B. } \\
\text { E. G. } \\
\text { R. P. } \\
\text { J. T. } \\
\text { B. S. } \\
\text { H. S. } \\
\text { N. T. } \\
\text { B. S. } \\
\text { C. M. } \\
\text { G. M. } \\
\text { Y. D. } \\
\text { A. A. } \\
\text { B. C. } \\
\text { A. A. } \\
\text { V. D. } \\
\text { M. L. } \\
\text { P. F. }\end{array}$ & $\begin{array}{l}\mathbf{A} \\
\mathbf{A} \\
\mathbf{A}\end{array}$ & $\begin{array}{l}\mathrm{A} \\
\mathrm{C}\end{array}$ & $\begin{array}{l}\mathbf{A} \\
\mathbf{A} \\
\mathbf{A} \\
\mathbf{A} \\
\mathbf{A} \\
\mathbf{A}\end{array}$ & $\begin{array}{l}\mathbf{A} \\
\mathbf{A} \\
\mathbf{A} \\
\mathbf{A} \\
\mathbf{A} \\
\mathbf{A} \\
\mathbf{A} \\
\mathbf{A} \\
\mathbf{A} \\
\mathbf{A}\end{array}$ & $\begin{array}{r}25 \\
11 \\
11 \\
11 \\
11 \\
2 \\
\\
11 \\
11 \\
11 \\
11\end{array}$ & $\begin{array}{r}\text { O } \\
\text { I } \\
\text { I } \\
\text { I } \\
\text { III } \\
\text { II } \\
\text { II } \\
\text { IV } \\
\text { III } \\
\text { III } \\
\text { II } \\
\text { II } \\
\text { III } \\
\text { I } \\
\text { II } \\
\text { IV } \\
\text { IV } \\
\text { III } \\
\text { I } \\
\text { I } \\
\text { I } \\
\text { I } \\
\mathbf{0} \\
\mathbf{0} \\
\mathbf{0} \\
\mathbf{0} \\
\mathbf{0} \\
\mathbf{I} \\
\mathbf{0} \\
\text { I } \\
\mathbf{0} \\
\mathbf{0} \\
\mathbf{0} \\
\mathbf{0} \\
\mathbf{0} \\
\text { IV }\end{array}$ \\
\hline
\end{tabular}

In the course of this study, it was found not only that the incidence of streptococcus carriers was high, but that with 2 exceptions, the children who harbored Group A streptococci carried a single type, Type 11 . In spite of the wide dissemination of this strain among a group of children living in close contact in an institution during the winter months, no cases of scarlet fever or streptococcus pharyngitis developed.

In studying the epidemiology of scarlet fever in Roumania, certain investigators (5) found that a sharp rise in the carrier rate of the epidemic strain preceded the outbreak of cases which they suggested might be taken as an indication that an epidemic was imminent. In spite of the fact that the number of children carrying Type 11 rose to about 66 per cent in early February, no cases of streptococcal infec- 
tion developed. This fact suggests either that this strain was of low pathogenicity or that the patients in the institution were insusceptible to the organism. It seems unlikely that so many children should be immune and it therefore appears more probable that the strain was only slightly virulent. Other authors (6) have reported similar findings. In a group of 108 rheumatic children, 22 became carriers of a single type, Type 33, and only one child developed a mild upper respiratory infection due to this strain. These authors are of the opinion that with organisms of low pathogenicity, a wide dissemination of a single type may occur unaccompanied by clinical disease.

\section{SUMMARY}

1. Despite the high incidence of carriers of Group A hemolytic streptococci of a single type, no disease attributable to these organisms developed among a group of crippled children under close observation in an institution.
2. An attempt to reduce the carrier rate by the topical administration of tyrothricin was unsuccessful.

\section{BIBLIOGRAPHY}

1. Schoenbach, E. B., Enders, J. F., and Mueller, J. H., The apparent effect of tyrothricin on Streptococcus hemolyticus in the rhinopharynx of carriers. Science, 1941, 94, 217.

2. Dubos, R. J., and Hotchkiss, R. D., The production of bactericidal substances by aerobic sporulating bacilli. J. Exper. Med., 1941, 73, 629.

3. Mueller, J. H., and Whitman, L., An improved method for the detection of hemolytic streptococcus carriers. J. Bact., 1931, 21, 219.

4. Fuller, A. T., The formamide method for the extraction of polysaccharide from haemolytic streptococci. Brit. J. Exper. Path., 1938, 19, 130.

5. Schwentker, F. F., Janney, J. H., and Gordon, J. E., The epidemiology of scarlet fever. Am. J. Hyg., 1943, 38, 27.

6. Kuttner, A. G., and Krumwiede, E., Observations on the epidemiology of streptococcal pharyngitis and the relation of streptococcal carriers to the occurrence of outbreaks. J. Clin. Invest., 1944, 23, 139. 